\title{
EDITORIAL
}

\section{Representación, escritura y conciencia histórica}

on sublime honor, se presenta la editorial de la Revista Debates por la Historia, volumen 7, número 2, correspondiente al periodo julio-diciembre de 2019.

Entre las discusiones actuales que se están dando en el campo de la historia y su consecuente aplicación a la historia de la educación, se presenta un asomo a tres conceptos clave que, aunque datan de tiempo atrás, siguen generando polémicas entre estos agrietamientos de lo que hoy se denomina la historia frente a las ideas del posmodernismo; así como su escritura, o más ubicuamente renombrada: historiografía. No está por demás rememorar y situar que en Latinoamérica -y concretamente en Chihuahua, México- las teorizaciones en el campo de la historia han estado en ocasiones ausentes, por ello la presentación de este número es -a la vez- una invitación a quienes jactanciosamente nos consideramos que hacemos historia, para que en nuestros escritos incorporemos la reflexión y diálogo con los textos y autores que están moviendo nuestra disciplina en estos tiempos posmodernistas, donde han llegado oleadas frescas para el enriquecimiento teórico y metodológico de la historia. Ya no es posible pensar nuestra disciplina en solitario, sino en relación y articulación con otras áreas como la antropología, filosofía, pedagogía y sociología, en las cuales se percibe que los límites que las separan se deslizan y se vuelven imperceptibles, permitiendo la performatividad en la investigación de nuestro territorio. 
Sin el deseo de hacer extensa la presentación de este número de la revista, se toca el concepto de la representación histórica, partiendo con una cita de Frank Ankersmit, profesor de estética, filosofía de la historia y teoría política de la Universidad de Groningen, Holanda; quien ha sido ubicado como posmodernista y seguidor de Hayden White. Ambos, hasta cierto punto, han negado las prácticas sociales del pasado, acercándose más a la vertiente del giro lingüístico en la historia. Las ideas de Ankersmit las usamos como herramienta para el análisis y la elaboración de juicios respecto al tema:

Desde mi punto de vista, la representación (histórica) es correctamente definida como un "hacer presente aquello que está ausente" -y esto es lo que la representación estética, histórica o política busca-. Por eso deberíamos tener más claro cuál es este "presente" al que queremos dar sentido, pues seguramente aquí no podría dársele a la palabra su significado "normal" (Ankersmit, 2006 p. I72).

La definición parece acertada dado que toda práctica histórica sólo puede ser representada, pero apelamos a que partan de la presencia y no de las ausencia, como se expresa en la cita anterior. También se desea precisar que el presente es este instante vivo existencial, lo que nos permite hacer esa distinción con el presente representado por las interpretaciones. Retomamos la idea posmodernista de que el pasado ya no existe físicamente y sólo tenemos huellas o vestigios con las cuales es posible la reconstrucción histórica, pero nunca

8 traer ese pasado al presente al grado de confundirlo, como sugiere Ankersmit. Por ello, el constructo de representación es a la vez la presencia de la realidad misma que investigamos, a través de la correspondencia indirecta con las fuentes, que son de utilidad para otorgar sentido y orientación ya no a la realidad pasada, sino a esta realidad viva presente, considerando su representación. 
No se argumenta que la historia sea ejemplar, ni maestra de la vida, ni que vayamos a cometer los mismos errores si no conocemos el pasado. Sin duda el pasado nos afecta en el presente y de allí la necesidad de considerarlo en el sentido de pertenencia humana y generacional. Recuperamos en este diálogo la cita de un joven historiador chileno, "la producción historiográfica es una reconstrucción intersubjetiva desde sujetos (historiadora/ historiador) que escrutan un pasado delimitado, operación que guarda correspondencia indirecta con la realidad estudiada, y que por tanto, evidencia representaciones consensuadamente verdaderas" (Ovalle, 2018 p. 190). Con esta idea se adiciona el criterio de verdad tan debatido en estos tiempos memorables del posmodernismo, verdad que tiene que estar presente en los textos históricos, pues lo que se conoce como relato histórico debe reflejarla, de lo contrario sería simplemente ficción, que desde la novela histórica es lo que comúnmente encontraremos y que es allí a donde nos direcciona el posmodernismo en la historia: a minimizar las prácticas sociales del pasado por las expresiones lingüísticas, en discurso del presente.

No se consideró el concepto de representación de Roger Chartier, exponente de la cuarta generación de la escuela de los Annales, quien lo discurre como una teoría de la correspondencia indirecta de los acontecimientos (descrito anteriormente), mismos que conocemos a través de las narraciones culturales en el tiempo. Con este autor nos estamos adentrando en lo que se conoce como la nueva historia, la historia cultural, para lo cual solo nombramos su obra El mundo como representación, lo que nos lleva a conocer que la historia se ha alejado de su nacimiento como disciplina científica nacida en el siglo XIX, esa historia pegada a las traducciones y a los Annales, perfilándose al estudio de los vínculos simbólicos. 
Retomar el concepto de Ankersmit tiene como fin acercarnos a lo que se dice del pasado desde el enfoque posmodernista, a estar en posición de realizar ajustes y empezar a revisar autores de esta postura teórica. En conclusión, el pasado es una reconstrucción y la disciplina de la historia con sus enfoques y metodologías nos ayuda a la representación de ese pasado investigado. La mirada hacia el pasado es siempre desde el presente, y es aquí en donde el resultado del acontecimiento investigado se convierte en escritura, el cual nos ilustra el autor Michell de Certeau, quien:

...publicaría L'Ecriture de l'Histoire, obra fundamental para el análisis de textos historiográficos y una revisión epistemológica de la historia en la que su autor reflexionó sobre los condicionantes que influyen particularmente sobre los historiadores y sus producciones historiográficas: a saber, el lugar social de producción, los procedimientos de análisis y la construcción de un texto (Elias, 2015, p. 67).

Lo investigado se convierte en escritura, misma que puede ser la tumba o la revivificación de los acontecimientos del pasado, sin embargo, no se desconoce que los lectores de esa escritura esperan haya un pacto de verdad en lo que leen, como resultado de la investigación basada en las referencias o fuentes historiográficas; pero tampoco se debe desconocer que la producción de discursos historiográficos responde al lugar en el cual se fabrican y a las subjetividades del investigador, las cuales tienen relación con su

10 situación posicional en la estructura económica, política y social que ocupa.

La llegada de la investigación al texto recorre caminos escabrosos, en esos rodeos intelectuales que se realizan con el fin de proporcionar la cognición del pasado que se hace presente por 
medio de la escritura. No se debe descartar por investigadores y lectores, que la aspiración es conocer la ocurrencia de un pasado, pero la interpretación estará mediada por los vínculos simbólicos construidos desde el presente y que pueden sucumbir al "canto de las sirenas" y narrarnos sociedades antagónicas o igualitarias, asignadas por parte del historiador, a lo que nos enuncia como (escritura) historiografía. No se trata ya -metafóricamente- de resucitar muertos y regresarlos a su tumba para que descansen aliviados de sus males y dolores, en todo caso está presente su rememoración, hacerles justicia mediante el sentido humanitario, en busca de sociedades ideales y en este sentido aventuramos que la historia tiene que ser esa disciplina que no se conforme con el rescate del pasado en bien de las identidades, sino que tiene que ir más allá en sus idealizaciones, tiene que ser pragmática, útil para este presente, para la cotidianidad de las prácticas sociales, con el sentido siempre emancipatorio. La historia tiene que ser un referente para las sociedades actuales.

Finalmente, el concepto de conciencia en el cual "las nociones claves para la articulación de la conciencia histórica son, a mi juicio, tres: historicidad, condición histórica y sentido histórico. Todas deben ser puestas en relación con la hermenéutica y la teoría de la historia" (Ovalle, 2019, p. 50). Conectamos el diálogo anterior con la noción de conciencia histórica: la historicidad, entendiendo por ello que todo tiene historia, lo que nos circunda, sea material, inmaterial o humano. Todo tiene origen, desarrollo dialéctico y su configuración en el presente; nada parte de la nada, siempre hay un pasado que está en el presente, por lo tanto, la categoría se aboca al pasado, el cual aun desconociéndose o no, hace presencia en lo actual. 
La condición histórica es el momento de la actualidad, de la existencia, el desarrollo en el cual la materia, ideas y los seres humanos configuran formas de vida deseables, propietarios de ideas y no supeditados a esquemas globales o generales que condicionan al ser, sino que es este quien construye sus condiciones y circunstancias en espacios concretos, espacios de interacciones. El sentido histórico está referido a las orientaciones, deseos, motivaciones para el futuro o más sencillamente expresado, representa el horizonte de expectativas, como lo concibe Koselleck, lo esperado, más allá de este presente que se está viviendo y que al estar en espera de su llegada ya forma parte de su presente, siendo por ello un futuro pensado que se hace parte del presente. Es por ello que la conciencia histórica la construyen los individuos, al darse cuenta de que todo presente tiene un pasado y que del presente se puede aspirar a un futuro, ambas temporalidades (pasado y futuro) están implicadas en el presente. Pero esta tríada de nociones que configuran la conciencia histórica, sólo adquiere significado desde un planteamiento hermenéutico, el cual para efectos de esta editorial se entiende como la forma en la cual se observa, imagina y se interpreta el mundo y la forma en la cual como seres humanos nos percibimos en él; finalmente, para arribar a lo que nos menciona el concepto de conciencia histórica, se tiene que ser reflexivo, crítico y propositivo.

Se mencionó al inicio del escrito que aquí se presenta sólo un asomo, con el fin de provocar la reflexividad de autores y textos que

12 en la actualidad están poniendo en movimiento nuevas ideas en la disciplina de la historia, en cualquiera de sus ramas, como es el caso de la educación. Estas novedades la han sacado de la exclusividad del estudio del pasado y trasladaron al fecundo mundo actual, por lo que su objeto de estudio es el presente y el pasado, con el apoyo de otras disciplinas que le son de utilidad. 
Con base en lo anterior, se describen los artículos que integran este número, esperando que el lector encuentre el pacto de verdad que el investigador de esta área le representa a través de las narraciones subsumidas en la escritura e insistiendo, lo trasladen a horizontes de expectativas futuras. Se estará entonces conforme por contribuir a la toma de conciencia histórica tan necesaria en este mundo antropogénico.

\section{Artículos en este número}

Las habilidades de pensamiento e informativas en el libro de texto de español: cronología de los planes de estudio en México nos presenta el análisis de los libros gratuitos del área de español del nivel primaria y sus distintas propuestas para la lectura y la escritura, haciendo una descripción de los métodos silábicos, fonéticos, globales, eclécticos y las marchas analíticas sintéticas, seguidas como procedimientos para su implementación. La visión que aquí se presenta parte de la perspectiva interpretativa apegada a lo pedagógico que, como centralidad, permite la asequibilidad del conocimiento de los educandos del primer grado que se inician en el mundo de lo simbólico.

El Surgimiento de la Federación de los Estudiantes y Campesinos Socialistas de México (FECSM) y el origen del "espíritu revolucionario" en el normalismo rural nos muestra las distintas formas de activismo social asumidas por los estudiantes normalistas, así como el impulso que se dio a sus movimientos, agrupados en la organización de la FECSM y su protagonismo durante el siglo XX. No está por demás mencionar que la asociación tenía raíces y tendencias de izquierda y su finalidad era la aplicación de los postulados de la Revolución, 
objetivados en la Constitución Política de 1917 y en la política posrevolucionaria del gobierno Cardenista.

La Historia de la cultura material: los bienes de una familia del siglo XVII en Parral, Chihuahua, nos muestra los pasajes de la vida cotidiana, sus usos y costumbres, la representación que se le daba a los testamentos para la herencia de los bienes materiales. Lo singular del artículo es que rescata la forma en que se heredaba la ropa de uso diario y esto nos muestra que no era sencillo tener vestimenta y mucho menos cuando eran familias de abolengo. El análisis se centra en una familia parralense y los inventarios de los bienes de uso diario a heredar. El escrito es un reflejo de la vida cotidiana y de la cultura de la época que se narra.

Influencia ideológica. La reconstrucción de un concepto: La Revolución Cubana y movimientos estudiantiles en Chihuahua durante la década de 1960, como su título lo sugiere, realiza la reconstrucción de un concepto que nos permite conocer sus atributos sui generis en relación a la influencia del movimiento cubano que desembocó en la revolución socialista, la cual vino a alimentar los movimientos de izquierda en México y concretamente en los estudiantiles de los años sesentas, como sucedió en Chihuahua. El artículo fue realizado con fuentes periodísticas y primarias correspondientes a la época.

La justicia social en la oratoria de Fidel Castro: potencialidades para el docente universitario de historia analiza la oratoria de Fidel Castro

14 Ruz, encontrando en ella valores que siguen predominando en el mundo y que incitan a su conservación y difusión entre las clases sociales marginadas del progreso social, económico y político. Sus discursos posicionan lo humano y el respeto como reivindicación de los derechos del hombre y de la mujer; así como las luchas a las 
cuales fue sometido el pueblo cubano por la oligarquía de los Estados Unidos de Norteamérica.

La Universidad Autónoma de Chihuahua, el contexto durante su creación en I954 realiza la narración histórica del surgimiento de la actual Universidad, visibilizando el contexto de los años en la primera mitad de los años cincuenta del siglo XX, lo que nos permite conocer las dificultades y el contexto agreste para que la institución surgiera, algo de lo que ya en nuestra época pocos rememoran. Se rescatan estadísticas poblacionales, económicas y culturales para el surgimiento -primero- del Instituto Literario de Chihuahua: los primeros planes de estudio, listados de personal académico y estudiantes. El texto rescata el sentido de esta institución en la actualidad, como formadora de generaciones que dan vida a la cotidianidad cultural chihuahuense de la que hoy gozamos.

\section{Reseñas}

Como es costumbre, se presenta en la revista la reseña de un libro y de una revista de historia en formato digital. El libro se titula Una generación desconocida. Movimiento social demócrata cristiano, 19621970. Testimonios y rescata el contexto en el cual surgió, que fue en el seno del Concilio Vaticano II, la Guerra de Vietnam, el grito hippie de "Amor y paz", la Revolución Cubana, los niños de Biafra, los asesinatos de Robert Kennedy y Martin Luther King, y los movimientos estudiantiles de Japón, Estados Unidos, Francia y México. Se menciona la influencia que tuvo en la población juvenil de ese tiempo, se presentan testimonios varios, lo que le da un toque de realismo de primera mano a lo aquí narrado. 
Reseña de La Bola. Revista de divulgación de la Historia es el segundo texto y nos menciona las viscisitudes de inicar un proyecto de esta envergadura con jóvenes seguidores de Clío, la musa de los historiadores y por qué no también, de Caliope, la musa de la poesia épica y la elocuencia, esto ante los embates de la historia con el enfoque del giro lingüístico o posmodernismo, que seguramente leeremos con avidéz en esta novel revista.

No resta sino desde aquí, desear una triunfal entrada a la publicación y difusión de artículos científicos de nuestra amada línea de trabajo, la historia e historiografía de la educación.

\section{Francisco Alberto Pérez Piñón}

\section{Director}

\section{Referencias}

Ankersmit, F. (2006). Representación, "presencia" y experiencia sublime. Historia y Grafía, (27). Recuperado de: http://www.redalyc.org/articulo.oa?id=589/58922905006

Elias Zeitler, T. (2015). Cuarenta años de La escritura de la Historia. Reflexiones en torno a la operación historiográfica, de Michel de Certeau a Paul Ricoeur. Historiografías, 9, pp. 6580. Recuperado de: https://dialnet.unirioja.es/servlet/articulo? codigo $=5321968$

Ovalle Pastén, D. (20I8). Roger Chatier y Paul Ricoeur: representación y verdad como fundamentos del trabajo historiador. Historia 396, 8(2), pp. I89-220. Recuperado de: 
https://www.academia.edu/38II2574/ROGER_CHARTIER_Y PAUL_RICOEUR_REPRESENTACI\%C $3 \% 93$ N_Y_VERDAD COMO FUNDAMENTOS DEL TRABAJO HISTORIADO $\underline{\mathrm{R}}$

Ovalle Pastén, D. (2019). Pensar la conciencia histórica contemporánea. Historicidad y teoría de la historia. En P. Aravena (ed.). Representación histórica y nueva experiencia del tiempo, pp. 49-63. Valparaíso, Chile: Editorial América en Movimiento SPA. Recuperado de: https://www.academia.edu/38818390/Pensar_la_conciencia_hi st $\% \mathrm{C}_{3} \% \mathrm{~B} 3$ rica contempor\% 3 C $\%$ Annea. Historicidad y teor \%C3\%ADa_de_la_historia 